medRxiv preprint doi: https://doi.org/10.1101/2022.01.23.22269711; this version posted January 24, 2022. The copyright holder for this preprint (which was not certified by peer review) is the author/funder, who has granted medRxiv a license to display the preprint in perpetuity.

All rights reserved. No reuse allowed without permission.

\title{
Detection of SARS-CoV-2 in Different Human Biofluids Using the Loop-Mediated Isothermal Amplification Assay: A Prospective Diagnostic Study in Fortaleza, Brazil
}

Marco Clementino ${ }^{1}$, Karene Ferreira Cavalcante ${ }^{2}$, Vania Angelica Feitosa Viana ${ }^{2}$, Dayara de Oliveira Silva ${ }^{1}$, Caroline Rebouças Damasceno ${ }^{1}$, Jessica Fernandes de Souza ${ }^{1}$, Rafhaella Nogueira Della Guardia Gondim", Daniel Macedo de Melo Jorge ${ }^{4}$, Lyvia Maria Vasconcelos Carneiro Magalhães ${ }^{1}$, Érico Antônio Gomes de Arruda $^{3}$, Roberto da Justa Pires Neto ${ }^{3}$, Melissa Soares Medeiros ${ }^{3}$, Armênio Aguiar dos Santos ${ }^{1}$, Pedro Jorge Caldas Magalhães ${ }^{1}$, Liana Perdigão Mello ${ }^{2}$, Eurico Arruda ${ }^{4,5}$, Aldo Ângelo Moreira Lima ${ }^{1,5}$, Alexandre Havt ${ }^{1}$.

${ }^{1}$ INCT-Biomedicina no Semiárido Brasileiro, Faculdade de Medicina, Universidade Federal do Ceará, Fortaleza, CE;

${ }^{2}$ Secretaria de Vigilância em Saúde e Laboratórios Central de Saúde Pública, Secretaria de Saúde do Ceará;

${ }^{3}$ Hospital S. José de Doenças Infecciosas e Transmissíveis, Secretaria de Saúde do Ceará, Fortaleza, CE; e

${ }^{4}$ Departamento de Biologia Celular e Molecular, Faculdade de Medicina, Universidade do Estado de S. Paulo, Ribeirão Preto, SP;

${ }^{5}$ Rede Vírus, Ministério da Ciência, Tecnologia, Inovações e Comunicações-MCTIC, Brasília, DF.

\section{Corresponding author}

Alexandre Havt

ahavt@ufc.br

Rua Coronel Nunes Melo, 1315. Rodolfo Teófilo, Fortaleza, CE - Brazil. 60430-270.

\section{Highlights}

- New nucleic acid amplification test for the diagnosis of SARS-CoV-2 using the RT-LAMP

- N5 primer set showed mutations in strains of interest, such as the gamma strain (P.1) of SARS-CoV-2

- When evaluated in combination N5 and Orf9 primer sets maintained high sensitivity and specificity

\section{Abstract}

We adopted the reverse transcriptase - loop mediated isothermal amplification (RT-LAMP) to detect SARS-Cov-2 in patient samples. Two primer sets for genes $N$ and Orf1ab were designed to detect SARS-CoV2, and one primer set was designed to detect the human gene Actin. We collected prospective 138 nasopharyngeal swabs, 70 oropharyngeal swabs, 69 saliva, and 68 mouth saline wash samples from patients suspected to have severe acute respiratory syndrome (SARS) caused by SARS-CoV-2 to test the RT-LAMP in comparison with the golden standard technique RT-qPCR. Accuracy of diagnosis using both primers, N5 and Orf9, was evaluated. Sensitivity and specificity for diagnosis was $96 \%$ (95\% Cl $87-99)$ and $85 \%(95 \% \mathrm{Cl} 76-$ 91 ) in 138 samples, respectively. Accurate diagnosis results were obtained only in nasopharyngeal swab processed via extraction kit. Accurate and rapid diagnosis could aid COVID-19 pandemic management by identifying, isolating, and treating patients rapidly.

\section{Keywords: Coronavirus, Molecular Diagnosis, RT-LAMP}

\section{Abbreviations}

COVID-19, coronavirus disease 2019; FBS, fetal bovine serum; HMPV, human metapneumovirus; NAAT, nucleic acid amplification test; RT-LAMP, reverse transcription loop-mediated isothermal amplification; PBS, phosphate-buffered saline; RT-qPCR, quantitative reverse transcription-polymerase chain reaction; RV-16, 
medRxiv preprint doi: https://doi.org/10.1101/2022.01.23.22269711; this version posted January 24, 2022. The copyright holder for this preprint

(which was not certified by peer review) is the author/funder, who has granted medRxiv a license to display the preprint in perpetuity.

All rights reserved. No reuse allowed without permission.

16 rhinovirus serotype 16; SARS-CoV-2, severe acute respiratory syndrome-coronavirus 2 ; $\mathrm{TCID}_{50}$, median tissue 17 culture infective dose; TPCK, tosylsulfonyl phenylalanyl chloromethyl ketone

18

19

50

;1

;2

;3

;4

Funding

This work was supported by grants from Conselho Nacional de Desenvolvimento Científico e Tecnológico (CNPq) [grant number 403548/2020-9] and Coordenação de Aperfeiçoamento Pessoal de Nível Superior - Programa Institucional de Internacionalização (CAPES-PRINT) [grant number 88887.593075/202000]. 
medRxiv preprint doi: https://doi.org/10.1101/2022.01.23.22269711; this version posted January 24, 2022. The copyright holder for this preprint (which was not certified by peer review) is the author/funder, who has granted medRxiv a license to display the preprint in perpetuity.

All rights reserved. No reuse allowed without permission.

\section{Introduction}

The American CDC and WHO recommend quantitative polymerase chain reaction (qPCR) as the gold standard nucleic acid amplification test (NAAT) for the molecular diagnosis of infectious diseases. However, alternative methods that can circumvent the time-consuming limitations and peculiar demands of laboratory infrastructure for qPCR should be considered, especially in developing countries. Ceará is one of the Brazilian states most affected by the COVID-19 pandemic, with an incidence of 6,434 per 100,000 inhabitants based on national official data in October 2021. The government institution responsible for the diagnosis of COVID-19 in Ceará is the Central Laboratory (LACEN-CE), which uses a qPCR routine that requires an average of $48-72 \mathrm{~h}$ to confirm the presence of SARS-CoV-2 in patient samples.

In this study, we partnered with LACEN-CE to develop a diagnostic test for SARS-CoV-2 using the reverse transcription loop-mediated isothermal amplification (RT-LAMP) technique [1]. We propose that RTLAMP would be faster, more accurate, and more reliable technique to detect SARS-CoV-2 in patient samples compared to conventional tests. LAMP is a single-step reaction that amplifies DNA or RNA using a single temperature of $65^{\circ} \mathrm{C}$, and a total time of execution of $40-60 \mathrm{~min}$. At the end of the amplification phase, the increased turbidity of the reaction would allow us to observe the result even with the naked eye.

Several scientific articles have already been published using the LAMP technique for the molecular diagnosis of pathogens [2-8]. Since the recent SARS-CoV-2 pandemic, several studies have been published worldwide on the methods of diagnosing COVID-19 using the RT-LAMP technique [9-13]. Such an accurate and rapid diagnosis could aid in COVID-19 pandemic management by identifying, isolating, and treating patients in a timely manner and could reduce LANCEN-CE time for diagnosis by half, removing the software analysis requirements.

\section{Materials and Methods}

\section{Primer design}

Primers were designed for the recognition of genes Orf1ab and N of SARS-CoV-2 using the PrimerExplorer version 5. Specificity and limit of detection of the primers were tested using plasmid positive controls for SARS-CoV-2 genes $N$ and Orf1ab and human RNaseP subunit 30 (HRP30) gene (IDT, Newark, 
NJ, USA) or from a human actin gene RT-qPCR amplicon produced with specific external LAMP primers F3

and B3. Best primers were selected for cross-specificity and limits of detection using other respiratory viruses and SARS-CoV-2 variants cultivated in vitro.

\section{Cultivation and isolation of viruses in vitro}

Influenza, rhinovirus serotype 16 (RV-16)-1A and -2, human metapneumovirus (HMPV), and SARS-

CoV-2 Brazil/SP-BR02/2020 virus stocks were propagated in cell cultures. Stocks were titrated by plaque assay and median tissue culture infectious dose $\left(\mathrm{TCID}_{50}\right)$ and then aliquoted and frozen at $-80^{\circ} \mathrm{C}$.

\section{$R T$-LAMP reaction}

We used the WarmStart Colorimetric RT-LAMP 2X Master Mix (New England Biolabs, Ipswich, MA, concentrated primer pool, $5 \mu \mathrm{L}$ of RNAse and DNAse free water, and $5 \mu \mathrm{L}$ of the tested sample. The plates were sealed and heated to $65^{\circ} \mathrm{C}$ for $60 \mathrm{~min}$. For the commercial kit used in this study the positive samples turned yellow, while the negative samples remained pink in color. considered positive for SARS-CoV-2 by RT-qPCR.

\section{$R T-q P C R$ diagnosis}

The gold standard method for COVID-19 diagnosis was performed using the RT-qPCR comprising primers and probes specific for SARS-CoV-2 $N$ and human genes (IDT, Newark, NJ, USA). Diagnosis performed in conjunction with a standard curve for viral load. Patient samples viral load was estimated using standard curves with efficiencies ranging from 95-105\%. Samples with a viral load of $\geq 1$ copy were 
medRxiv preprint doi: https://doi.org/10.1101/2022.01.23.22269711; this version posted January 24, 2022. The copyright holder for this preprint (which was not certified by peer review) is the author/funder, who has granted medRxiv a license to display the preprint in perpetuity.

All rights reserved. No reuse allowed without permission.

$10 \quad$ The chosen primers set for the genes $N$ and Orf1ab were subjected to mutation rate analysis. We

selected 3844 sequences from Brazilian SARS-CoV-2 complete genome sequences from GISAID on March 18, 2021. These sequences were aligned using the Clustal W software (Ver. 1.2.4) [14] and mutation rates were calculated using the following formula: mutation rates = number of sequences with mutations/total number of sequences.

\section{Ethical approval}

This proposal was approved by the National Ethical Review Board on 06/10/2020 with the code CAAE 33460220.7.0000.5045. Data collected from the research participants were kept confidential.

\section{Sample size and statistical analysis}

Estimation of the required population size for this proposal was calculated with statistical power set to at least $80 \%$, and confidence was set to be at least $95 \%[15,16]$. Considering the prevalence of COVID-19 as $50 \%$ positive, we estimated that 62 patients suspected of SARS-CoV-2 would be sufficient to determine the sensitivity and specificity of the test. Having a natural loss of $15 \%$ of these patients, a total of 71 patient samples were collected [17].

RT-LAMP results were classified as true positive (TP), false positive (FP), false negative (FN), or true negative (TN) based on the RT-qPCR test results using RNA extracted from nasopharyngeal samples as templates. Positive predictive values (PPV), positive negative values (PNV), sensitivity, and specificity were calculated using GraphPad Prism software (ver. 8.4.0) [18].

\section{Prospective study design}

This study was divided into two stages to test the detection accuracy of SARS-CoV-2 in human biofluids of SARS suspected patients in Ceará, a northeastern state of Brazil.

Patients of the first stage of this study were screened for SARS symptoms in primary care units in the state of Ceará. Then, 71 SARS suspected individuals' nasopharyngeal swabs samples were collected and aliquoted blindly by our collaborators at LACEN-CE. During the second stage of this study, patients were 
medRxiv preprint doi: https://doi.org/10.1101/2022.01.23.22269711; this version posted January 24, 2022. The copyright holder for this preprint (which was not certified by peer review) is the author/funder, who has granted medRxiv a license to display the preprint in perpetuity.

All rights reserved. No reuse allowed without permission.

screened for SARS symptoms by health care employees at the São José Hospital, a public hospital in

Fortaleza, Ceara, Brazil. Our second set of 71 patients' samples suspected to have the SARS-CoV-2 infection

comprised nasopharyngeal swabs, oropharyngeal swabs, saliva, and mouthwash with saline solution. Study

population demographics is shown in Supplementary table 1.

Prior to diagnosis, $300 \mu \mathrm{L}$ of the nasopharyngeal swab samples was used for RNA extraction via automatic magnetic beads RNA isolation using CHEMAGIC 360-D (PerkinElmer, Waltham, MA, USA) or MagMax viral RNA isolation kit (Applied Biosciences, Los Angeles, LA, USA). The isolated RNA was used for SARS-CoV-2 diagnosis via RT-qPCR and RT-LAMP assays. The remaining swab volume $(600 \mu \mathrm{L})$ of nasopharyngeal swabs of stage 1 were heated at $98^{\circ} \mathrm{C}$ for 30 min to isolate RNA from samples by the boiling collected and submitted for SARS-CoV-2 diagnosis via RT-qPCR and RT-LAMP assays.

\section{Results}

\section{SARS-CoV-2 diagnosis kit primer design}

Five sets of primers were designed for the $N$ gene of SARS-CoV-2, but only N5 reacted exclusively to the $N$ gene-positive control (yellow color in Figure 1A). The in vitro limit of detection for N5 reached one copy of its positive control (IDT, Newark, NJ, USA) (Figure 1B). Four sets of primers were designed for the Orf1ab gene of SARS-CoV-2, but only Orf9 reacted exclusively to the Orf1ab positive control (IDT, Newark, NJ, USA) (yellow color in Figure 1C). The in vitro limit of detection for Orf9 was 1000 copies of its positive control (Figure 1D). The results showed that primers set N5 and Orf9 could be used to detect SARS-CoV-2 using sequences of SARS-CoV-2 plasmids.

To complete the diagnostic kit, we used a primer set to detect a human gene to use as an internal control. Five sets of human actin primers were designed. The Actin158 primer set showed specificity for the positive control and were selected for our study (yellow color in Figure 1E).

We confirmed the reaction specificity by testing the RT-LAMP primer sets N5 and Orf9 in a reaction with other respiratory viruses obtained in vitro. The results showed that the new RT-LAMP primer sets developed for the detection of SARS-CoV-2 were reactive to SARS-CoV-2 isolates from different variants 
(Wuhan, Dorigan, P1, and P2) (yellow color in Figure 1F). Additionally, the new RT-LAMP primer sets did not react with other viruses tested (Figure 1F).

Next, we investigated primer sets mutation rates. The mutation rates of the N5 primers (F3, B3, FIP, $\mathrm{BIP}$, and LF) were lower than 2\%; however, the mutation rate of the N5 primer LB was $16.8 \%$ (Figure 2A). We observed that $\sim 50 \%$ of these mutations were found in clades GR and P1 (Figure 2B and 2C). Alignment analysis of the Orf9 primer set showed mutation rates lower than $2 \%$ for all six primers (Figure 2D). Alignment of the SARS-CoV-2 genome with the N5 primer set showed a single nucleotide mutation in clades GR and P1. The mutation was characterized as a single nucleotide substitution of the nucleotide guanine for cytosine (Figure 2E). To test the hypothesis of higher false-negative rates of primer set N5, we tested both primer sets in an RT-LAMP reaction with serial dilutions of SARS-CoV-2 variants cultured in vitro. The results confirmed that primer set N5 was less reliable than Orf9, as it had a lower limit of detection (Figure 2F and 2G). Considering these results, we would recommend using both primer sets for the detection of SARS-CoV-2 in human samples.

\section{Alternative methodologies for the detection of SARS-CoV-2 via RT-qPCR and RT-LAMP}

During the first stage of this study, we investigated whether different RNA extraction methods could influence the detection of SARS-CoV-2 in nasopharyngeal samples. Thus, we performed RNA isolation using an RNA isolation kit with magnetic beads and the boiling method (i.e., heat). The results showed an increase in the CT range for RT-qPCR reactions of both Orf1ab and $N$ in samples extracted by heat, as their CT median was higher than 30. In contrast, the samples extracted using the commercial extraction kit had a CT median of approximately 22 cycles (Figures 3A and 3B). As expected, we also observed a significant decrease in viral load in nasopharyngeal samples extracted by heat treatment (Figure 3C and 3D). Overall, these results demonstrate that the boiling method did not preserve viral RNA in the nasopharyngeal samples used in this study.

During the second stage of this study, 71 patients with SARS symptoms had nasopharyngeal swabs, oropharyngeal swabs, saliva, and mouthwash with saline solution samples collected. Our results showed that among the four body biofluids collected, the nasopharyngeal swab was the only one which CT was maintained 
medRxiv preprint doi: https://doi.org/10.1101/2022.01.23.22269711; this version posted January 24, 2022. The copyright holder for this preprint (which was not certified by peer review) is the author/funder, who has granted medRxiv a license to display the preprint in perpetuity.

All rights reserved. No reuse allowed without permission.

)1 at a detectable range, and nasopharyngeal swabs had the highest viral load (Figure 3E and 3F). Diagnostic predictive values indicated that only nasopharyngeal swabs extracted using the RNA extraction kit can be used for the diagnosis of SARS-CoV-2 (Supplementary Tables 2, 3, 4 and 5).

\section{Diagnosis of SARS-CoV-2 via RT-LAMP after the extraction of sample RNA}

We validated the newly developed RT-LAMP SARS-CoV-2 detection kit (Actin158, Orf9, and N5) by submitting 138 extracted RNA from nasopharyngeal swab samples for RT-LAMP diagnosis (Figure 4A, 4B, and 4C). As expected, the internal control, Actin158, showed a positive result for all samples, except for the negative control (Figure 4A). Results obtained by RT-qPCR and RT-LAMP diagnosis is shown in

\section{Supplementary Table 6.}

We compared the LAMP results to qPCR in terms of RT-qPCR CT value, viral load, and LAMP assay color (Figure 4D and 4F). We observed that samples with a viral load higher than $1 \mathrm{copies} / \mu \mathrm{L}$ of Orf1ab were positive for SARS-CoV-2 via RT-qPCR assay using the primer set Orf9 (Figure 4E). Samples with a viral load higher than 28 copies/ $\mu \mathrm{L}$ were positive for SARS-CoV-2 via the RT-LAMP assay using primer set N5 (Figure 4G).

Next, we calculated the sensitivity, specificity, positive predicted values (PPV), and negative predicted values (NPV) for RT-LAMP diagnosis using primer sets N5 and Orf9, comparing their diagnosis with the RTqPCR diagnosis (Table 1). We considered all samples positive for viral load higher than 1 copies/ $\mu \mathrm{L}$, and the results are summarized in Table 1. Based on these results, we suggest that primer sets Orf9 and N5 should be used in combination for the diagnosis of SARS-CoV-2 in patients with SARS symptoms using nasopharyngeal swab samples. A representative diagnosis using combined analysis and results using the RT-LAMP SARSCoV-2 detection kit is illustrated in Supplementary Figure 1. Sensitivity and specificity for combined diagnosis were $96 \%$ (95\% Cl 87-99) and 85\% (95\% Cl 76-91), respectively. The PPV and NPV values for the combined diagnosis were $80 \%(95 \% \mathrm{Cl} 69-88)$ and $97 \%$ (95\% Cl 90-99), respectively.

\section{Discussion}


medRxiv preprint doi: https://doi.org/10.1101/2022.01.23.22269711; this version posted January 24, 2022. The copyright holder for this preprint (which was not certified by peer review) is the author/funder, who has granted medRxiv a license to display the preprint in perpetuity.

All rights reserved. No reuse allowed without permission.

In the State of Ceará, the official laboratory (LACEN-CE) routinely identifies the presence of SARS-

CoV-2 in nasopharyngeal swabs via RT-qPCR after RNA extraction using commercial kits. On average,

approximately $4 \mathrm{~h}$ are required for RNA extraction and qPCR test execution. However, it takes $48-72$ hours to

release official results. This time-consuming issue motivated us to pursue a new faster NAAT using RT-LAMP.

This technique uses the Bst DNA polymerase, isolated in 1968 [20] from the thermophilic bacterium

Geobacillus stearothermophilus, which has a strand displacement activity and requires a set of six primers.

The SARS-CoV-2 RT-LAMP NAAT developed here consists of three sets of primers, two of which are used for the identification of SARS-CoV-2 (N5 and Orf9), while one acts as the internal control to identify the was extracted using a magnetic beads RNA extraction kit. Then, samples were submitted for diagnosis of

SARS-CoV-2 using RT-qPCR and the new NAAT RT-LAMP developed for the diagnosis of SARS-CoV-2 using $N$ and Orf1ab genes. The predictive diagnostic values obtained for PPV were greater than $80 \%$, whereas the NPV values were greater than $85 \%$ for Orf9 and N5. Considering these results, we recommend using these sets of primers in combination for the diagnosis of SARS-CoV-2.

We also investigated the possibility of using an alternative methodology to simplify RNA extraction from patient samples. We tested the diagnosis of SARS-CoV-2 from nasopharyngeal swab samples using RNA extracted only by heat. However, we were unable to efficiently detect SARS-CoV-2 in these samples, most likely because the viral RNA content was not preserved after RNA extraction procedures. Considering this, we would not recommend using RNA extracted by the boiling method as template for the NAAT RT-LAMP developed here. Our study also identified that samples preserved in viral transport medium (VTM) interfered with the LAMP enzyme amplification reaction. Samples preserved in the VTM had a high rate of false positives. Thus, all samples were collected in PBS. 
medRxiv preprint doi: https://doi.org/10.1101/2022.01.23.22269711; this version posted January 24, 2022. The copyright holder for this preprint (which was not certified by peer review) is the author/funder, who has granted medRxiv a license to display the preprint in perpetuity.

All rights reserved. No reuse allowed without permission.

During the second stage of this study, samples of nasopharyngeal swabs, oropharyngeal swabs, saliva,

and mouthwash in saline solution from SARS suspected patients were collected to test the predictive power of the new NAAT developed here. However, the results confirmed that only nasopharyngeal swab samples were suitable for the diagnosis of SARS-CoV-2 using the primer sets N5 and Orf9.

This study developed and validated a new nucleic acid amplification test for the diagnosis of SARSCoV-2 using the RT-LAMP technique. The Orf9 and N5 primer sets showed low mutation rates, except for the primer LB from N5 set. Despite that, when evaluated in combination with the Orf9 primer set, our NAAT was able to maintain high sensitivity and specificity. This methodology could reduce the time required to release the official diagnosis by half as this new methodology does not require analysis of results using specific software programs.

\section{References}

1. Notomi, T., et al., Loop-mediated isothermal amplification of DNA. Nucleic Acids Res, 2000. 28(12): p. E63.

2. Yamazaki, W., et al., Development and evaluation of a loop-mediated isothermal amplification assay for rapid and simple detection of Campylobacter jejuni and Campylobacter coli. J Med Microbiol, 2008. 57(Pt 4): p. 444-451.

3. Fukuda, S., et al., Rapid detection of norovirus from fecal specimens by real-time reverse transcriptionloop-mediated isothermal amplification assay. J Clin Microbiol, 2006. 44(4): p. 1376-81.

4. Ito, M., et al., Rapid detection and typing of influenza $A$ and $B$ by loop-mediated isothermal amplification: comparison with immunochromatography and virus isolation. J Virol Methods, 2006. 135(2): p. 272-5.

5. Parida, M.M., et al., Rapid and real-time detection of Chikungunya virus by reverse transcription loopmediated isothermal amplification assay. J Clin Microbiol, 2007. 45(2): p. 351-7.

6. Chowdry, V.K., et al., Development of a loop-mediated isothermal amplification assay combined with a lateral flow dipstick for rapid and simple detection of classical swine fever virus in the field. J Virol Methods, 2014. 197: p. 14-8.

7. Silva, S., et al., Development and Validation of Reverse Transcription Loop-Mediated Isothermal Amplification (RT-LAMP) for Rapid Detection of ZIKV in Mosquito Samples from Brazil. Sci Rep, 2019. 9(1): p. 4494.

8. Karanis, P., et al., Development and preliminary evaluation of a loop-mediated isothermal amplification procedure for sensitive detection of cryptosporidium oocysts in fecal and water samples. Appl Environ Microbiol, 2007. 73(17): p. 5660-2.

9. Huang, W.E., et al., RT-LAMP for rapid diagnosis of coronavirus SARS-CoV-2. Microb Biotechnol, 2020. 13(4): p. 950-961.

10. Yan, C., et al., Rapid and visual detection of 2019 novel coronavirus (SARS-CoV-2) by a reverse transcription loop-mediated isothermal amplification assay. Clin Microbiol Infect, 2020. 26(6): p. 773779. 
11. Park, G.S., et al., Development of Reverse Transcription Loop-Mediated Isothermal Amplification Assays Targeting Severe Acute Respiratory Syndrome Coronavirus 2 (SARS-CoV-2). J Mol Diagn, 2020. 22(6): p. 729-735.

12. Yu, L., et al., Rapid Detection of COVID-19 Coronavirus Using a Reverse Transcriptional Loop-Mediated Isothermal Amplification (RT-LAMP) Diagnostic Platform. Clin Chem, 2020. 66(7): p. 975-977.

13. Baek, Y.H., et al., Development of a reverse transcription-loop-mediated isothermal amplification as a rapid early-detection method for novel SARS-CoV-2. Emerg Microbes Infect, 2020. 9(1): p. 998-1007.

14. Sievers, F., et al., Fast, scalable generation of high-quality protein multiple sequence alignments using Clustal Omega. Mol Syst Biol, 2011. 7: p. 539.

15. Shea, J.A., et al., Revised estimates of diagnostic test sensitivity and specificity in suspected biliary tract disease. Arch Intern Med, 1994. 154(22): p. 2573-81.

16. Nori, S., et al., Sensitivity and specificity of reflectance-mode confocal microscopy for in vivo diagnosis of basal cell carcinoma: a multicenter study. J Am Acad Dermatol, 2004. 51(6): p. 923-30.

17. Bujang, M.A. and T.H. Adnan, Requirements for Minimum Sample Size for Sensitivity and Specificity Analysis. J Clin Diagn Res, 2016. 10(10): p. Ye01-ye06.

18. Trevethan, R., Sensitivity, Specificity, and Predictive Values: Foundations, Pliabilities, and Pitfalls in Research and Practice. Frontiers in Public Health, 2017. 5(307).

19. Alcoba-Florez, J., et al., Fast SARS-CoV-2 detection by RT-qPCR in preheated nasopharyngeal swab samples. medRxiv, 2020: p. 2020.04.08.20058495.

20. Stenesh, J., B.A. Roe, and T.L. Snyder, Studies of the deoxyribonucleic acid from mesophilic and thermophilic bacteria. Biochim Biophys Acta, 1968. 161(2): p. 442-54.

\section{Author Contributions}

Marco Clementino - Conceptualization, Data curation, Formal Analysis, Investigation, Methodology, Project Administration, Manuscript writing original draft, review and editing, Funding Acquisition.

Karene Ferreira Cavalcante, Vania Angelica Feitosa Viana, Dayara de Oliveira Silva, Caroline Rebouças Damasceno, Jessica Fernandes de Souza - Formal Analysis, Methodology, Validation, data curation.

Rafhaella Nogueira Della Guardia Gondim, Daniel Macedo de Melo Jorge, Lyvia Maria Vasconcelos Carneiro Magalhães, Liana Perdigão Mello - Methodology, Project administration

Érico Antônio Gomes de Arruda, Roberto da Justa Pires Neto, Melissa Soares Medeiros - Medical assistance, investigation.

Armênio Aguiar dos Santos, Pedro Jorge Caldas Magalhães, Eurico Arruda, Aldo Ângelo Moreira Lima Conceptualization, Project supervision, Investigation, Manuscript review and editing.

Alexandre Havt - Conceptualization, Data curation, Formal Analysis, Investigation, Methodology, Project Administration, Manuscript writing original draft, review and editing, Funding Acquisition 
medRxiv preprint doi: https://doi.org/10.1101/2022.01.23.22269711; this version posted January 24, 2022. The copyright holder for this preprint (which was not certified by peer review) is the author/funder, who has granted medRxiv a license to display the preprint in perpetuity.

All rights reserved. No reuse allowed without permission.

17 Tables

I8 Table 1 - Predictive validity of the RT-LAMP SARS-CoV-2 detection kit in nasopharyngeal swab

19 samples extracted by extraction kit

20

\begin{tabular}{|c|c|c|c|c|c|c|c|}
\hline \multicolumn{8}{|c|}{ Extraction Kit - Nasopharyngeal Swab } \\
\hline \multicolumn{8}{|c|}{ RT-LAMP N5 } \\
\hline \multicolumn{2}{|c|}{ Sensitivity } & \multicolumn{2}{|c|}{ Specificity } & \multicolumn{2}{|c|}{ PPV } & \multicolumn{2}{|c|}{ NPV } \\
\hline Value & $95 \% \mathrm{Cl}$ & Value & $95 \% \mathrm{Cl}$ & Value & $95 \% \mathrm{Cl}$ & Value & $95 \% \mathrm{Cl}$ \\
\hline 0.78 & 0.65 to 0.87 & 0.95 & 0.88 to 0.98 & 0.91 & 0.79 to 0.96 & 0.88 & 0.80 to 0.93 \\
\hline \multicolumn{8}{|c|}{ RT-LAMP Orf9 } \\
\hline \multicolumn{2}{|c|}{ Sensitivity } & \multicolumn{2}{|c|}{ Specificity } & \multicolumn{2}{|c|}{ PPV } & \multicolumn{2}{|c|}{ NPV } \\
\hline Value & $95 \% \mathrm{Cl}$ & Value & $95 \% \mathrm{Cl}$ & Value & $95 \% \mathrm{Cl}$ & Value & $95 \% \mathrm{Cl}$ \\
\hline 0.96 & 0.87 to 0.99 & 0.87 & 0.78 to 0.92 & 0.82 & 0.70 to 0.89 & 0.97 & 0.90 to 0.99 \\
\hline \multicolumn{8}{|c|}{ RT-LAMP Orf9 and N5 } \\
\hline \multicolumn{2}{|c|}{ Sensitivity } & \multicolumn{2}{|c|}{ Specificity } & \multicolumn{2}{|c|}{ PPV } & \multicolumn{2}{|c|}{ NPV } \\
\hline Value & $95 \% \mathrm{Cl}$ & Value & $95 \% \mathrm{Cl}$ & Value & $95 \% \mathrm{Cl}$ & Value & $95 \% \mathrm{Cl}$ \\
\hline 0.96 & 0.87 to 0.99 & 0.85 & 0.76 to 0.91 & 0.8 & 0.69 to 0.88 & 0.97 & 0.90 to 0.99 \\
\hline
\end{tabular}




\section{Figure Legends}

Figure 1. Reaction specificity and detection limit tests. A - Representative results of the specificity of the RT-LAMP reaction using the N5 primer set and control plasmids for the human HRP30 gene, the $N$ gene of SARS-Cov-2 and for the Orf1ab gene of SARS-CoV-2. B - Representative results of the detection limit of the RT-LAMP reaction using the N5 primer set and the control plasmid for the SARSCoV-2 $\mathrm{N}$ gene. C - Representative results of the specificity of the RT-LAMP reaction using the primer set Orf9 and the control plasmids for the human HRP30 gene, the SARS-Cov-2 Orf1ab gene and the $N$ gene of SARS-CoV-2. D - Representative results of the detection limit of the RT-LAMP reaction of the Orf9 primer set and the control plasmid for the SARS-CoV-2 Orf1ab gene. E - Representative results of the specificity of RT-LAMP reaction using primer set Actin158 and positive control for human Actin gene and control plasmids for SARS-Cov-2 gene N and SARS-CoV-2 gene Orf1ab. Negative Control, Neg Ctrl; X, empty well. F - Representative results of specificity of the RT-LAMP reaction with viral samples cultured in vitro using primer sets N5 and Orf9.

Figure 2. Primer sets mutation rate. A - Mutation rate of the N5 primer set obtained from the alignment analysis of 3844 Brazilian SARS-CoV-2 sequences. B - N5-LB primer mutation rate in the GR clade by Brazilian state. C - Mutation rate of primer N5-LB in the clade P1 by Brazilian state. D - Mutation rate of the Orf9 primer set obtained from the alignment analysis of 3844 Brazilian SARS-CoV-2 sequences. E Consensus sequence of mutations in the N5-LB sequence. F - Representative limit of detection results of the RT-LAMP reaction using the N5 primer set in samples of SARS-CoV-2, Variant P1 and variant P2 cultured in vitro. G - Representative results of the detection limit of the RT-LAMP reaction using the Orf9 primer set in samples of SARS-CoV-2, Variant P1 and Variant P2 cultured in vitro.

Figure 3. Alternative methodologies for the detection of SARS-CoV-2 via RT-qPCR and RT-LAMP. A Violin plot of CT values obtained from RT-qPCR of nasopharyngeal swab samples whose RNA was extracted via RNA extraction kit or extracted via the boiling method using primers for the detection of the Orf1ab gene of SARS-CoV-2. B - Box plot of CT values obtained from RT-qPCR of nasopharyngeal 
medRxiv preprint doi: https://doi.org/10.1101/2022.01.23.22269711; this version posted January 24, 2022. The copyright holder for this preprint (which was not certified by peer review) is the author/funder, who has granted medRxiv a license to display the preprint in perpetuity.

All rights reserved. No reuse allowed without permission.

swab samples whose RNA was extracted via RNA extraction kit or extracted via the boiling method using primers for the detection of the $\mathbf{N}$ gene of SARS-CoV-2. C - Mean of viral load obtained from RTqPCR of nasopharyngeal swab samples whose extracted via RNA extraction kit or extracted via the boiling method using primers for the detection of the Orf1ab gene of SARS-CoV-2. D - Mean of viral load obtained from RT-qPCR of nasopharyngeal swab samples whose RNA was extracted via RNA extraction kit or extracted via the boiling method using primers for the detection of the $\mathrm{N}$ gene of SARS-CoV-2. E - Box plot of CT values obtained from RT-qPCR of Saliva, Saline mouth wash, Oropharyngeal swab, and nasopharyngeal swab samples whose RNA was extracted via RNA extraction kit using primers for the detection of the Orf1ab gene of SARS-CoV-2. F - Mean of viral load obtained from RT-qPCR of Saliva, Saline mouth wash, Oropharyngeal swab, and nasopharyngeal swab samples whose RNA was extracted via RNA extraction kit using primers for the detection of the Orf1ab gene of SARS-CoV-2

Figure 4. Representative results of SARS-CoV-2 diagnosis via RT-qPCR and RT-LAMP from 71 human RNA samples extracted from nasopharyngeal swabs via an automated magnetic bead extraction kit. AC - Representative RT-LAMP results from 24 human nasopharyngeal swabs whose RNA samples were extracted via automated magnetic bead extraction kit. D - RT-qPCR CT values and viral load using Orf1ab SARS-CoV-2 primers plotted against RT-LAMP diagnostic results using Orf9 primer set of nasopharyngeal swabs samples whose RNA samples were extracted via automated magnetic bead extraction kit. D' - range of RT-qPCR CT values with median of all 71 nasopharyngeal swab. E - RTqPCR CT values and viral load using Orf1ab SARS-CoV-2 primers plotted against RT-LAMP diagnostic results using Orf9 primer set of nasopharyngeal swabs samples whose RNA samples were extracted via automated magnetic bead extraction kit; the $X$ axis indicates the maximum $C T$ value of 35 for detection limit evaluation. F - RT-qPCR CT values and viral load using N SARS-CoV-2 primers plotted against RT-LAMP diagnostic results using N5 primer set of nasopharyngeal swabs samples whose RNA samples were extracted via automated magnetic bead extraction kit. F' - range of RT-qPCR CT 
17 values with median of all 71 nasopharyngeal swab. G - RT-qPCR CT values and viral load using $\mathbf{N}$

78 SARS-CoV-2 primers plotted against RT-LAMP diagnostic results using N5 primer set of

79 nasopharyngeal swabs samples whose RNA samples were extracted via automated magnetic bead

30 extraction kit; the $\mathrm{X}$ axis indicates the maximum CT value of 35 for detection limit evaluation.

31 ** RT-LAMP results were given a number from 0 to 2 according to the color of the reaction results. The

32 pink color reactions were assigned the number 0 , the orange color reactions were assigned the

33 number 1, and the yellow color reactions were assigned the number 2. Each number and color are

34 shown on the $\mathrm{X}$-axis on the right. 


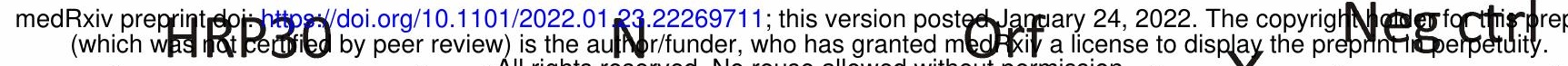

1

All rights reserved. No reupe allpwed without permission.

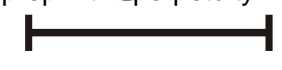

$A$
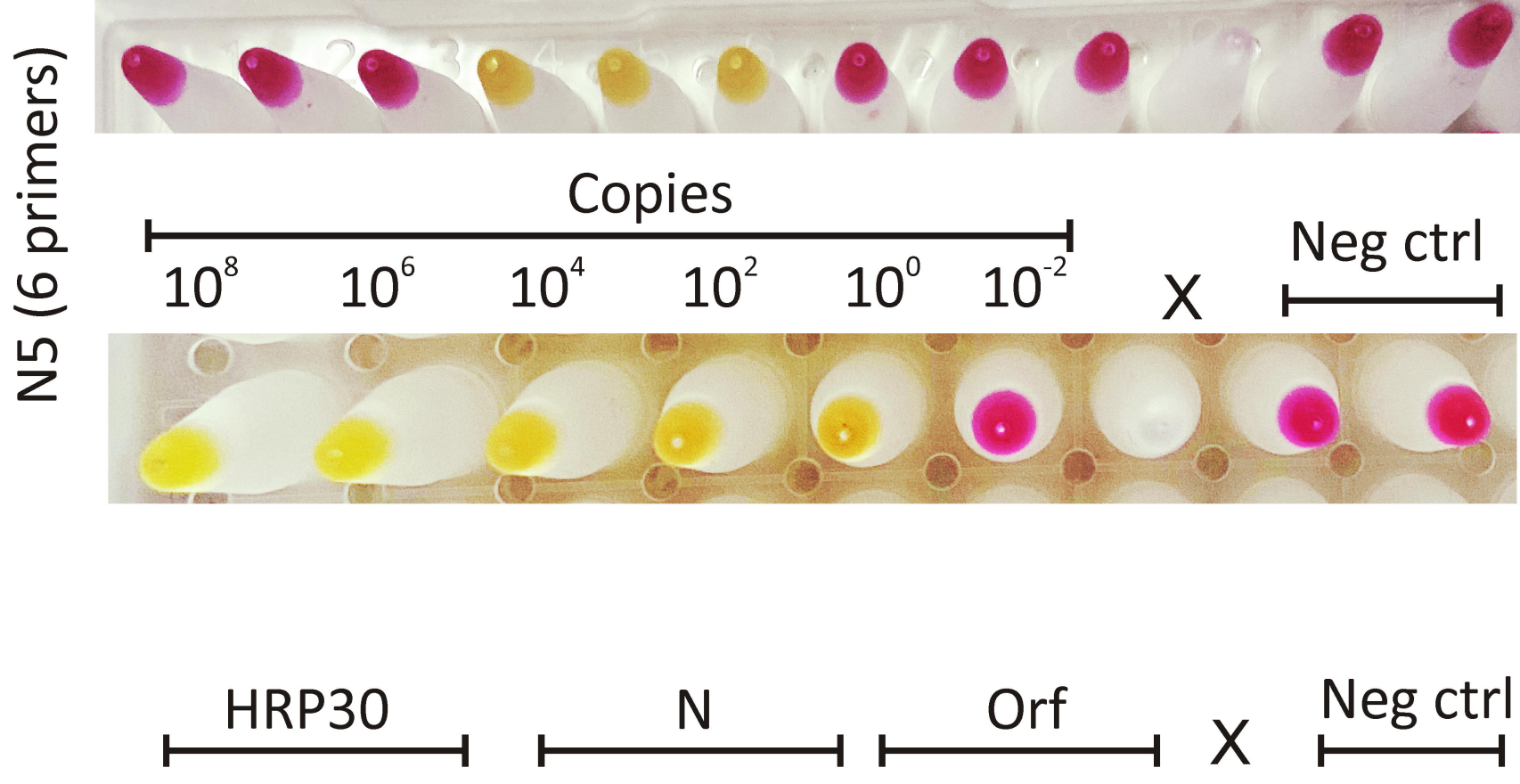

Neg ctrl

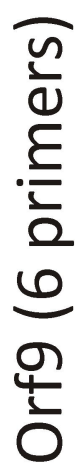

Copies

$\begin{array}{llllllll}10^{6} & 10^{5} & 10^{4} & 10^{3} & 10^{2} & 10^{1} & 10^{0} & 10^{-1}\end{array} \times \stackrel{\text { Neg ctrl }}{\longmapsto}$
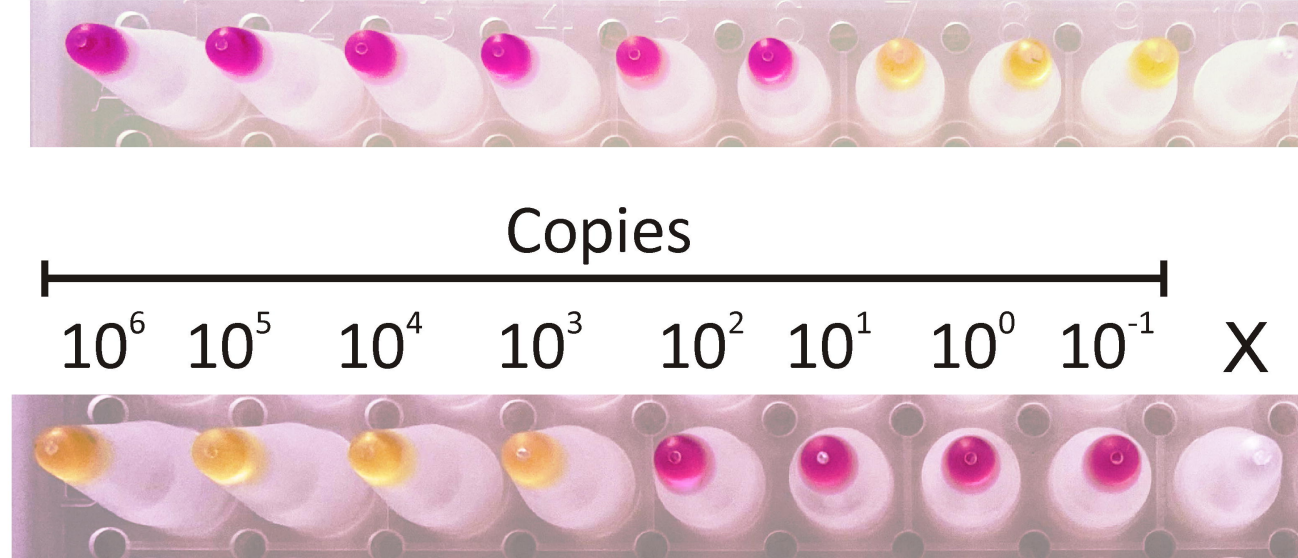

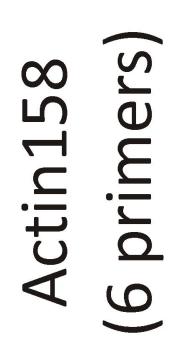

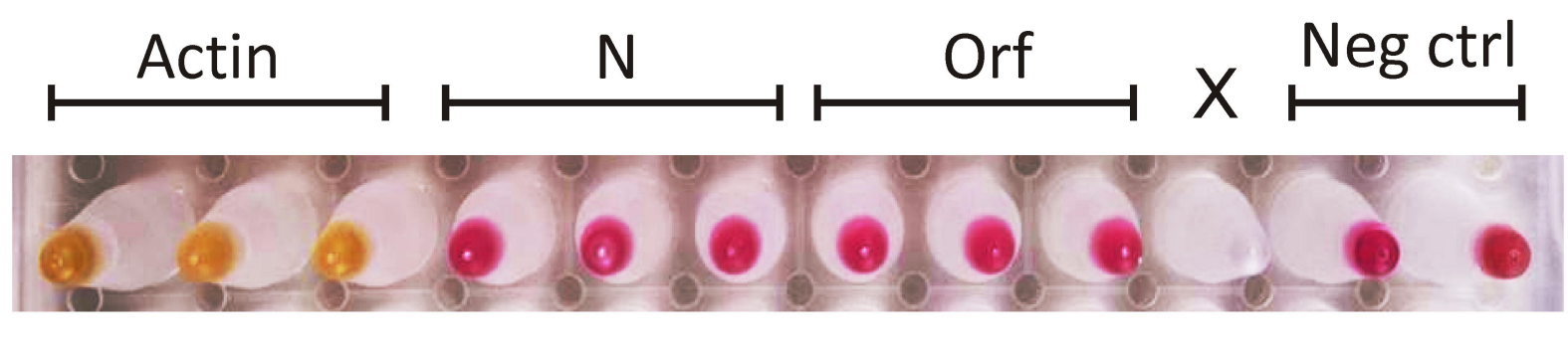

SARS-CoV-2

N5 
A
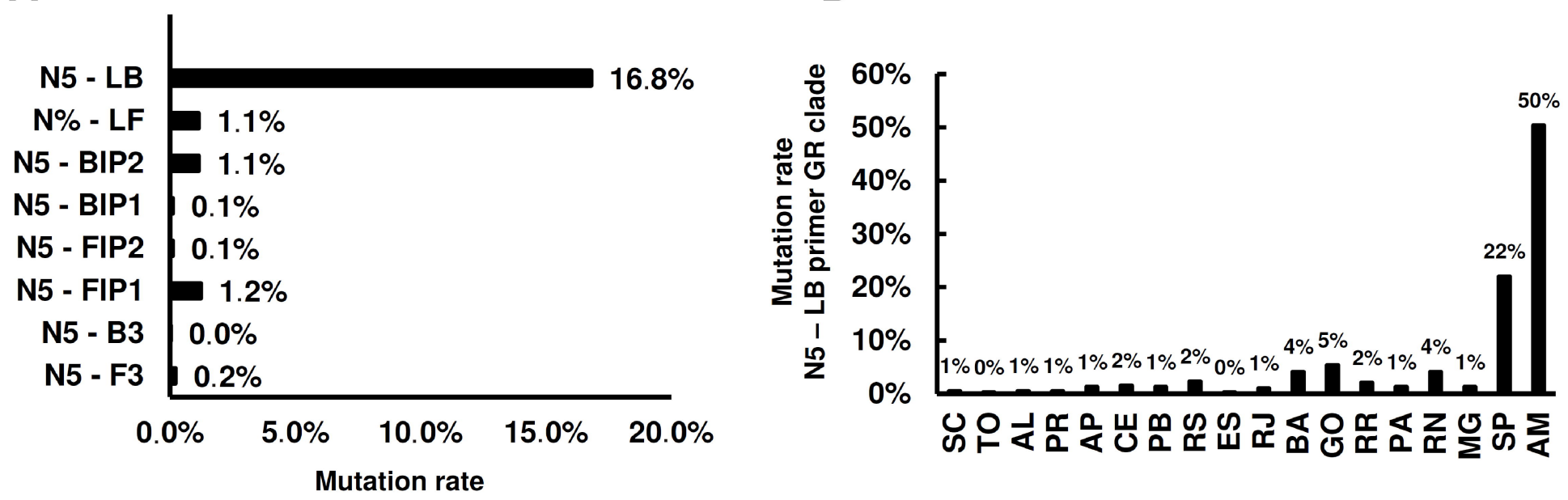

C

D
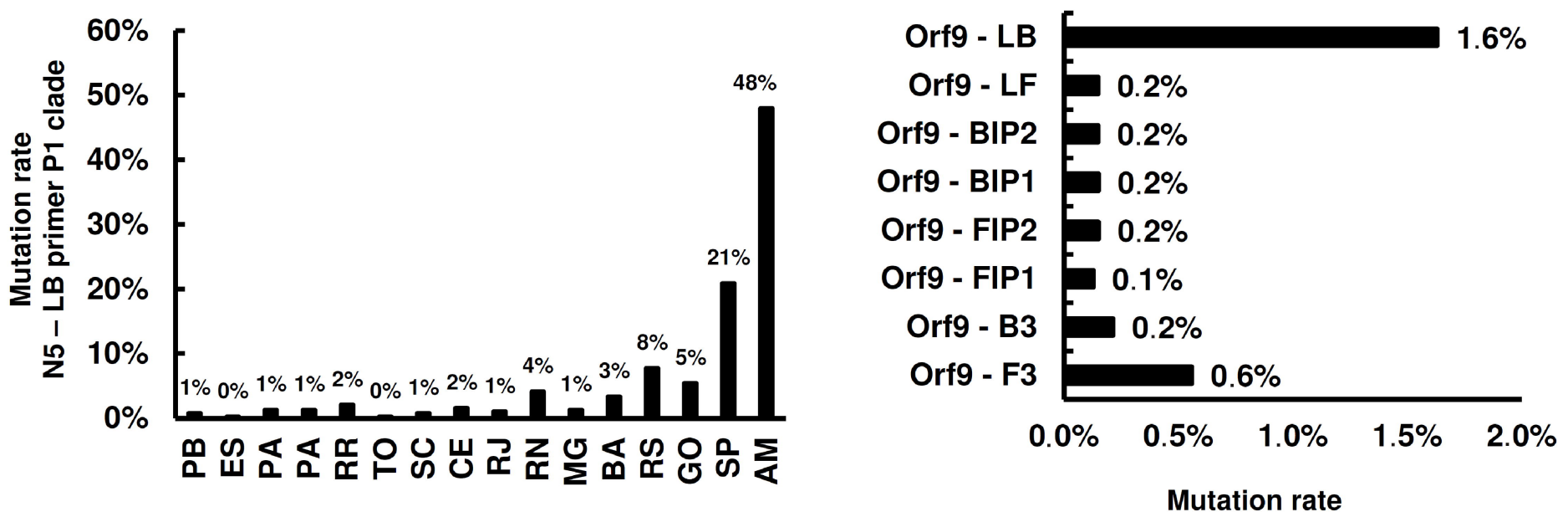

E

SARS-CoV-2 P1

SARS-CoV-2 GR
TTCCAATTAACACCAATAGCAGTC:

TTCCAATTAACACCAATAGCAGTC:
$\mathbf{F}$

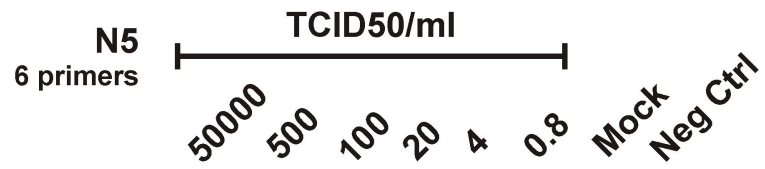

SARS-CoV-2

SARS-CoV-2 P1

SARS-CoV-2 P2

G

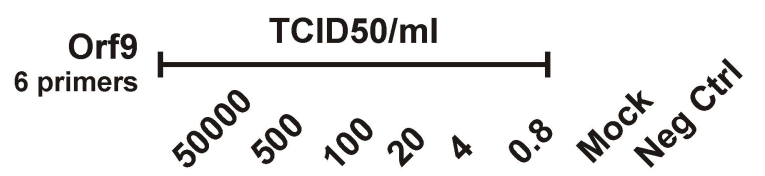

SARS-CoV-2

SARS-CoV-2 P1

SARS-CoV-2 P2

$\mathrm{X}$

X $\mathrm{X}$ 
$\frac{\text { ID }}{1-12}$ Internal Control - Human Actin

13-24

Neg

Pos

SARS-CoV-2 - gene N

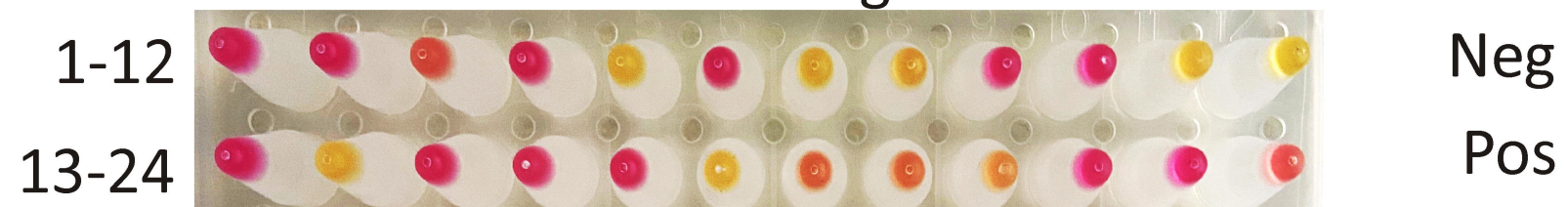

SARS-CoV-2 - gene Orf1ab

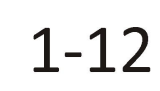

13-24

Orf9

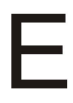

Neg

Pos

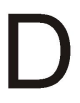

N

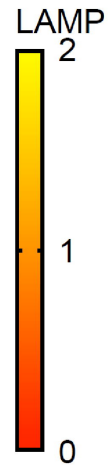

20

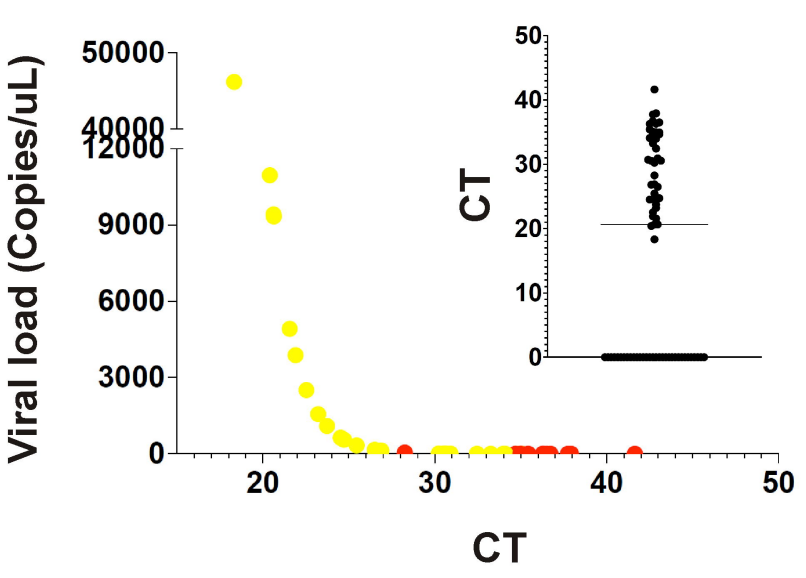

$40 \quad 50$

CT

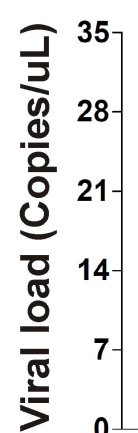

20

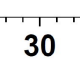

Orf9

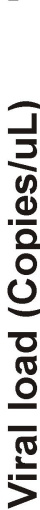

300000

200000

100000

75000

50000

25000
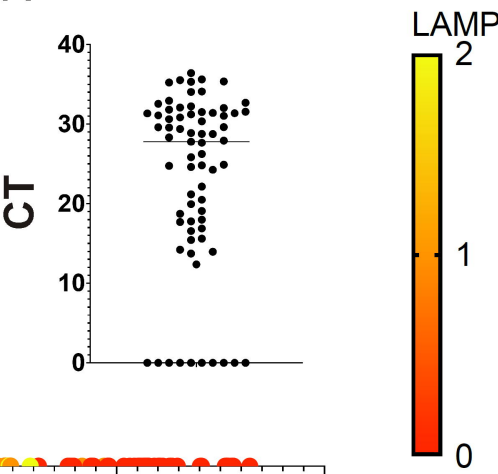

9

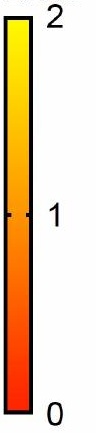

CT

N
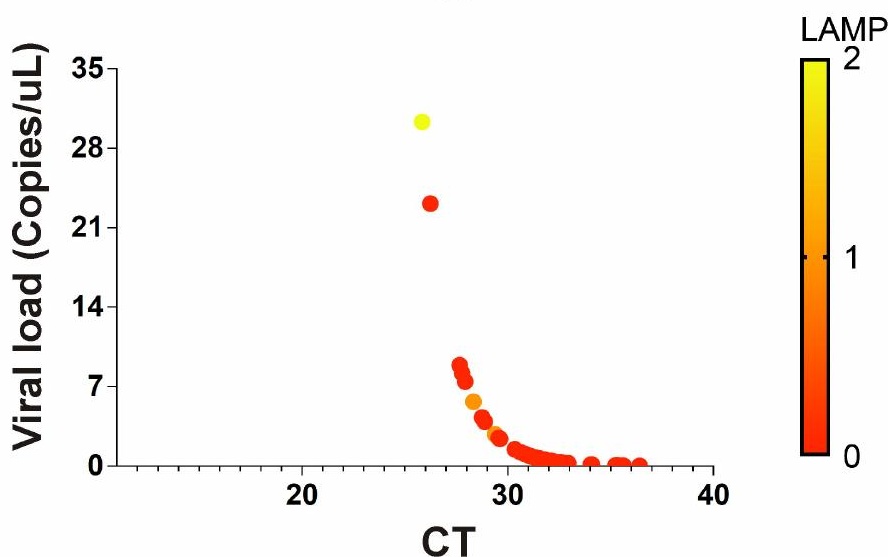
CT 